Western University

Scholarship@Western

Aboriginal Policy Research Consortium International (APRCi)

8-18-2009

\title{
Beyond Recovery: Colonization, Health and Healing for Indigenous People in Canada
}

Lynn F. Lavallee

Jennifer M. Poole

Follow this and additional works at: https://ir.lib.uwo.ca/aprci

Part of the Other Mental and Social Health Commons

Citation of this paper:

Lavallee, Lynn F. and Poole, Jennifer M., "Beyond Recovery: Colonization, Health and Healing for Indigenous People in Canada" (2009). Aboriginal Policy Research Consortium International (APRCi). 254.

https://ir.lib.uwo.ca/aprci/254 


\title{
Beyond Recovery: Colonization, Health and Healing for Indigenous People in Canada
}

\author{
Lynn F. Lavallee • Jennifer M. Poole
}

Received: 18 May 2009 / Accepted: 5 August 2009 /

Published online: 18 August 2009

(C) Springer Science + Business Media, LLC 2009

\begin{abstract}
How do we limit our focus to mental health when Indigenous teaching demands a much wider lens? How do we respond to mental health recovery when Indigenous experience speaks to a very different approach to healing, and how can we take up the health of Indigenous people in Canada without a discussion of identity and colonization? We cannot, for the mental health and recovery of Indigenous people in Canada have always been tied to history, identity, politics, language and dislocation. Thus, in this paper, our aim is to make clear that history, highlight the impacts of colonization and expound on Indigenous healing practices taking place in Toronto. Based on findings from a local research project, we argue these healing practices go beyond limited notions of recovery and practice, offering profound and practical ways to address the physical, emotional, spiritual and mental health of Indigenous peoples.
\end{abstract}

Keywords Indigenous health · Indigenous healing $\cdot$ Mental health $\cdot$ Colonization and mental health $\cdot$ Recovery

\section{Introduction}

Over the last hundred years, the Western field of mental health has been the site of various competing systems, visions and models including moral hygiene and psychiatric rehabilitation. Indigenous worldviews and knowledge systems have not been part of these competing systems. In Canada, the medical model of categorization, pathologization and treatment has proven the most powerful, effectively shaping how mental health is talked about and practiced in hospitals, institutions and most community agencies (Poole 2007).

There have been a number of challenges to the dominance of the medical model of mental illness including anti-psychiatry in the 1960's, consumerism in the 1980's and entrepreneurism in the 1990's (Church 2004). Grounded in the lived experience of people as they accept and overcome mental disability (Deegan 1988), mental health recovery styles

L. F. Lavallee $(\bowtie) \cdot$ J. M. Poole

Ryerson University, Toronto, ON, Canada

e-mail: lavallee@ryerson.ca 
itself as the next great challenge to the medical model. Challenges from Indigenous communities are surfacing, particularly related to the lack of culturally appropriate services (Blackstock 2008). This paper will explore the notion of mental health recovery and how this model can be extended or augmented by Indigenous knowledge.

\section{Mental Health Recovery}

Born of longitudinal research (see Harding et al. 1986a, b for example), and the experience of recovered patients in the United States (Deegan 1988), the central argument of the recovery model is that with certain conditions (Jacobson and Greenley 2001) such as hope, empowerment, peer support, self-care and medication, recovery from mental illness is not only possible but probable (Mead and Copeland 2000). Proponents of the related recovery vision for mental health reason dollars are better spent if channeled towards such recoveryoriented supports as assertive community treatment (ACT) teams and wellness recovery action programs (WRAP). WRAPs include wellness activities such as light exercise classes, nutrition programs, peer counseling, journaling and sleep (Mead and Copeland 2000). These supports are supposed to be more cost-effective than emergency room visits. They are also meant to create hope and a sense of personal responsibility (Carpenter 2002; Jimenez 1988).

Sounding so good, recovery has taken the mental health world by storm (Jacobson and Curtis 2000), its acceptance cemented when George Bush's administration incorporated recovery principles into its platform for mental health. New Zealand has also adopted recovery principles for mental health service delivery, as has Scotland, areas of the United Kingdom and Europe. Beginning in 2002, recovery talk appeared in Ontario (Poole 2007), and 7 years on, the recovery vision continues to re-shape mental health practice and policy. Indeed, it is now expected that mental health practitioners not only embrace but also utilize the concepts inherent in mental health recovery when working with patients, consumers, clients and survivors. These workers are to focus on empowerment, hope, rights and a more holistic approach to care. They are also to assume that their clients and patients will one day be well. Yet, what constitutes recovery's more holistic approach to mental health? What are the limits of peer support and personal responsibility, and why do some claim that, despite best intentions, recovery is still a Western middle class club meant only for those who can afford this particular kind of empowerment (Cheng et al. 2008)? Blackstock (2008) notes that a consequence of favouring Western knowledge is the disregard of the knowledge systems of Indigenous peoples, including understandings of mental health. Mental health programs are typically based on Western knowledge "with some modifications made" for Indigenous peoples (Blackstock 2008, p. 2). The recovery model must also recognize that Indigenous peoples have their own knowledge systems that can augment, extend and ultimately strengthen this approach.

A recent community based participatory research project in Toronto made Blackstock's point clear, in that most advocates of mental health recovery are white with little attention given to culture and racism (Cheng et al. 2008; Poole 2008). Indigenous peoples have been curiously absent from the Canadian recovery scene. Reasons for this nonparticipation may be traced to the racism and whiteness that continues in mental health (Poole et al. (2009), Whiteness, privilege and mental health recovery. Unpublished paper), but might there also be a link to the limitations of recovery, including its specific focus on mental health?

For Indigenous people, an exploration of that which has been categorized as mental health by Western medical practitioners needs to start with Indigenous teachings related to 
holistic health. Although specific Nations, even within the same country, have different teachings that need to be acknowledged, for this particular paper we are drawing on the teachings that are a reflection of the Anishnaabe Nation of Turtle Island. However, the teachings described may be similar to the teachings of other Nations. The Anishnaabe Nation is comprised of the Algonquin, Ojibwe, Oji-Cree and Odawa Nations (Eigenbrod et al. 2003). Turtle Island is a term used by many Anishnaabe when referring to North America.

\section{Indigenous Practices and Seven Generations Teaching}

Seven Generations Teaching: What we do today impacts the next seven generations to come. Conversely, what happened in the past seven generations impacts us today.

The Seven Generations Teaching is a concept that is part of many North American Indigenous cultures, specifically the Anishnaabe. Many understand this teaching as what you do today affects the next seven generations. We can have a positive impact on the next seven generations or a negative impact depending upon our choices as individuals and as a collective. This teaching also reflects upon knowing your ancestors, the past seven generations. If you do not know where you have come from you will not know where you are going.

\section{Impact of Colonization on Health}

Colonization has had a direct influence on the Seven Generations Teaching. Colonial activities, both past and present, have attempted to strip Indigenous people of their cultural identity and land. In Canada, legislation such as the Gradual Civilization Act of 1857 and the Indian Act (1874, amended in 1985) has and continues to determine who is status Indian (as recognized by the Federal government) as well as controlling education, health and the land of Indigenous people. The residential school legacy is Canada's most marked blemish where children were forcibly removed from their homes and placed in residential schools where many faced horrific abuse from the 1940's, with the last school closing in 1996 (Dion Stout and Kipling 2003). As a result of Canadian legislation, Indigenous people were banned from participating in their spiritual ceremonies (Roberts 2004), physically reprimanded for speaking their language in residential schools (Wesley-Esquimaux and Smolewski 2004), and today, Indigenous children are still apprehended by child welfare agencies at an alarming rate (Trocme et al. 2004). Similar activities have occurred globally with boarding schools in the United States, New Zealand and Australia (Armitage 1995; Buti 2002). Indeed, the trauma of colonization has left a void in many Indigenous people with respect to their identity, both collectively and individually.

The legacy of colonization and the current colonial activities against Indigenous people has an impact on Indigenous peoples' mental health (Kirmayer et al. 2000). In particular, the statistics on suicide for American Indian (AI) and Alaskan Native (AN) youth in the United States is 2 to 2.5 times higher and non-AI and non-AN (U.S. Department of Health and Human Services 2001), 2 to 3 times higher in Aboriginal people in Australia (ElliottFarrelly 2004) and up to seven times higher in Aboriginal people in Canada (Health Canada 2006). While a direct link between colonization and suicide is difficult to demonstrate 
empirically, "the potential transgenerational links between these [colonial] social practices and suicide can be traced" (Kirmayer et al. 2007, p.10). These colonial social practices, such as residential school, child welfare, the 60's and millennium scoop (Sinclair 2007), past and current land reclamations that are occurring globally, environmental dispossession (Richmond and Ross 2009), the lack of history from an Indigenous perspective in our educational institutions and the overt and covert racism experiences by Indigenous people contribute to "denigration of identity" (Kirmayer et al. 2007, p.79), cultural genocide, grief, anger, hopelessness and helplessness. All of these factors are linked to suicide (Colmant 2000), mental health and recovery.

\section{Holistic Understanding of Health}

To understand and better respond to the mental health of Indigenous people one needs to reflect upon what mental health means to Indigenous people. One of the teachings of the Algonquin and Ojibwe Nations is the Medicine Wheel, however, other Nations share similar teachings. The Medicine Wheel teachings are vast and within these teachings is an understanding of health and well-being. A healthy state is based on balance between four interconnected realms: the physical, mental, emotional and spiritual (National Aboriginal Health Organization 2005). The mental realm refers to the mind and/or intellect, not the Western definition of mental health. The four realms cannot be understood separately and the Western concept of mental health can only be understood in relation to physical, mental/ intellectual, emotional and spiritual well-being. Sickness begins with the spirit, if the spirit is wounded - because of the principle of interconnectedness - the mind, emotions and body become sick. Colonization has wounded the spirit of Indigenous peoples and this is one of the reasons for ill health amongst Indigenous people globally. True healing includes reestablishing a balance between these four realms (Anishnawbe Health Clinic 2006).

\section{Indigenous Health Practices in Canada}

Aboriginal communities in Canada have an abundance of culturally specific programs targeting addictions and/or mental health. The Ontario Federation of Indian Friendship Centres produces numerous documents that help guide programs related to addiction and mental health. For instance, an Aboriginal Youth Drug Strategy includes a Harm Reduction Trainer's Manual (Aboriginal Youth Drug Strategy 2009). This program consists of various group workshops infusing education on harm reduction with cultural and spiritual practices. The opening of each workshop session begins traditionally with a purification ceremony or smudge. A purification ceremony involves the burning of plant medicines, typically sage or sweet grass. The sage or sweet grass is lit with a match and burned. The smoke from the sage or sweet grass can cleanse a room, people or objects (V. Harper, personal communication, July 20, 2003). Participants sit in a circle and with the opening smudge the spiritual Grandmothers and Grandfathers are called upon to join their circle. The Harm Reduction Trainer's Manual includes learning about specific addiction strategies, such as harm reduction but explains it or draw parallels to cultural teachings such as the Seven Generations.

Mainstream agencies have also merged Indigenous approaches within their programs. The Centre for Addiction and Mental Health (CAMH) in Toronto employs an Aboriginal Elder as a counselor in their Aboriginal Services department. The Elder is recognized for 
his Indigenous knowledge rather than for any certificates, diplomas or degrees in counseling. He, as well as the other Aboriginal counselors, visit agencies throughout the city that service Aboriginal people. Spiritual ceremonies, such as smudging are part of the activities undertaken by Aboriginal Services at CAMH.

Similar to the work on the WRAPs discussed earlier where mental health recovery programs incorporate holistic wellness, other Indigenous strategies as defined by the Medicine Wheel teachings have a direct impact on mental health and addiction. The North American Indigenous Games (NAIG) is one such venue. The NAIG is a sport competition for Canadian and American Indigenous people held every three years (North American Indigenous Games 2002). The NAIG began in 1990 with the most recent games held in British Columbia in 2008.

A Health and Social Impact Survey administered to participants of the 2008 NAIG demonstrated that participants felt the games increased their pride as Aboriginal people and helped them understand more about their own culture and other Indigenous cultures (Lavallée et al. 2009), an important factor in healing the identity of Indigenous people. The Health and Social Impact Survey also found that approximately $56 \%$ of respondents indicated that they did not smoke cigarettes or do drugs and approximately $40 \%$ did not drink alcohol. Of the respondents who did smoke, do drugs or drink, 84\% strongly agreed or agreed that participating in the NAIG helped them cut down or quit doing drugs; $78 \%$ strongly agreed or agreed that participating in the NAIG helped them cut down or quit smoking; and $73 \%$ strongly agreed or agreed that participating in the NAIG helped them cut down or quit drinking alcohol. The positive impact of the NAIG on cultural identity and substance use was substantiated in this study.

\section{Indigenous Identity}

However helpful the above programs are, we also argue that real healing for Indigenous Peoples must include work around identity. The cultural identity of Indigenous peoples is one of the primary aspects that colonization has attacked and continues to attack. Ill health, including what the West calls mental ill health, is a symptom of this attack on cultural identity. Treating the symptoms of ill health, including addiction and mental health is a band-aid solution that does not treat the root causes - colonization and identity disruption. If one recognizes that the assault on cultural identity has played a significant role on the ill health of Indigenous people and that the spirit has been wounded, then healing activities need to include rebuilding the individual and collective identity of Indigenous peoples. This includes a spiritual understanding of the individual and collective Indigenous culture.

In order to understand how to heal the individual and collective identity of Indigenous Peoples we need to explore the colonial impact on identity. Kirmayer et al. (2000) argue that the attempted forced assimilation and resulting cultural genocide of Indigenous people has left many people with "profound problems of identity and self-esteem" (p. 6). Building on this work, a qualitative research project was conducted in Toronto over a period of three years. It explored the impacts of a physical activity and cultural program and through story-telling, highlighted many issues around colonization, identity, self-esteem and health (Lavallée 2007, 2008).

\section{The Program}

The physical activity and cultural program offered at the Native Canadian Centre of Toronto (NCCT) combined martial arts with cultural teachings (Native Canadian Centre 2006). It 
included physical activity, mental/intellectual challenges, emotional support/sharing circles and spiritual teachings about Aboriginal culture, such as the Medicine Wheel.

The NCCT is one of the oldest Friendship Centres in Canada. The NCCT has been a meeting place for Aboriginal people since the early 1960's and was one of the first friendship centres that came out of the 1950's Friendship Centre Movement (National Association of Friendship Centres 2006). The Friendship Centre Movement began when an increased number of Aboriginal people were moving to large urban areas of Canada. Friendship centres would offer counselling on matters of employment, housing, education, health and liaison with other community organizations. Today, the National Association of Friendship Centres reports over 100 friendship centres across Canada each with programming that meet the needs of their community.

\section{Sharing Circle Method of Gathering Stories}

In this research project, participants shared stories through sharing circles. The use of sharing circles in Indigenous research has been described as circle methodology, a method that can be familiar and comforting for Indigenous research participants because the circle has a long tradition in Indigenous cultures (Restoule 2006). In addition, storytelling is a practice of many Indigenous people and is reflective of the oral traditions (Baskin 2005). Sharing circles are similar to focus groups, however the former incorporate culturally appropriate protocols (Lavallée 2009).

\section{The Participants' Stories}

Participants shared many difficult stories about their pasts and what they had lived through. This included suicide attempts, addiction, depression, cutting, eating disorders and violence. However, participants also discussed how participating in the program at the NCCT and cultural practices/ceremonies, such as drumming and sweats contributed to their healing. Sweats are spiritual purification ceremonies that involve building a small lodge with a pit in the centre that is filled with hot stones or what are called Grandfather and/or Grandmothers. Water placed on the Grandfather and Grandmothers produce heat (V. Harper, personal communication, July 20, 2003).

I had attempted suicide twice in my life by taking a lot of pills both times, once when I was 13 or 14 and the other was 5 years ago in my thirties. Over the course of 20 years or so, I went to different western medicine things-psychologists, psychiatrists, different programs - and after my suicide attempt they sent me to see a social worker and then from there they put me in a program. I went once and that was it! I had a bad experience with the doctor who was running the program. A few years later, I had a really bad, evening or day and cried all night. The next day I went to an Elder - the first time I spoke with an Elder - and told him about my situation and that I was distraught. He sent me to Council Fire for a program that was being done there. After that program was done I checked out the Native Canadian Centre website to see if there were any programs for healing. I saw the [martial arts] program and thought I have to come. That led me to learning more about who I was as Anishnaabe Qwe [Aboriginal woman]. I participated in other cultural activities like sweats, drumming and full moon ceremonies (Marten). 
I don't know what I would have done. I don't think I would have done something crazy, but all of the things I have learned from [martial arts] has kept me somehow sane through all the craziness... (Redman).

Why I wanted to take martial arts for me, you grow up with alcoholism and violence- for me personally-you feel vulnerable. You grow up, you always have to look over your shoulder. You don't feel love or respect. You're constantly fighting. Why I wanted to do martial arts was to feel empowered (White Spider).

Most of my friends were victims of child abuse as well. They were slapped and beaten by their parents, so we ended up forming a little group of gangs that did drugs and alcohol for stress release (Bruce).

When I first started here, I was in school full-time. I wasn't working enough and I had no money. Because of this, I wasn't really doing too well, emotionally. I got involved in things even after starting the martial arts program that were not really healthy for me. I remember going in and just sitting on the floor and thinking about what I had just done and feeling bad about it. But if I didn't have [martial arts] I don't know where I would have been. Maybe I would have been at home doing self-harming behaviour (Marten).

In addition to healing, identity was another of the themes to emerge from the participants' stories. The following story captures how foster care has been and currently is a tool of the colonizer (Trocmé et al. 2004) and has lead to not understanding one's identity.

I'm adopted and I was told that I would always live with that need [knowing who you are] no matter where I go. I'm second generation in foster care. Unless I have kids of my own I can't see any change...I have tons of cousins, but don't feel any connection whatsoever...The only thing they [relatives] identify with being Native is the status card (Nimky Nene).

A sub-theme within identity was the stigma of being and/or identifying as Aboriginal. The following are some of the stories:

...my identity can be concealed but inside I can't hide it. I was born up North and got darker in the summer and people treated you differently, but in Toronto, everyone is different. No one can tell what you are. But I grew up in lower income areas (Marten).

I took a chance on coming to Toronto... I have always admired the fact that with a change of location you can have a change of character. You can be whoever you want to be when people don't know you. Whenever I was moving somewhere I could always pretend that I was somebody else. I could always be the best that I wanted to be, not someone's perception of what I was. Moving to Toronto, I was able to escape the stigma of being a distressed and violent young person (Bruce).

The following discussion between three Aboriginal women highlights a challenge amongst many Aboriginal people who self-identify but do not look like a stereotypical Indian. Subsequently, they are challenged about their identity, both by non-Aboriginal people and Aboriginal people.

Marten: Stepping through the doors [attending the Native Canadian Centre of Toronto] I was scared...I didn't know if I would be accepted because I didn't look that Native but I see that I am accepted here. 
White Spider: I know what you mean.

Turtle: You [referring to Marten] look very Native. I don't look Native.

White Spider: What's an Indian supposed to look like anyway?

And this final story demonstrates the internalized oppression that Aboriginal people have learned to place on themselves and/or other Aboriginal people.

I realize that strong male Native positive role models are not abundant in my life experience. Only recently I'm a comfortable and okay with Native men. My issue when I first started [participating in the physical activity program at the Native Canadian Centre] was, "He's Native [referring to the instructor], what the heck can he know? ... He's Native, what can he show me?" (Turtle)

All of these stories highlight how identity is negotiated with respect to societal expectations and discrimination. The stigma of identifying as Aboriginal and the internalized oppression that exists contribute to a lack of cultural pride. For those that do identify, if they do not fit societies' stereotypical view of what an Indian looks like their identity is challenged.

Related to these issues is another that presented itself over and over again in the project- $\mathrm{a}$ sense of undeservingness or low self esteem. Some made clear that being Native meant you are somehow less than and do not deserve good things.

Somebody said something to me and I had to kinda set him straight. He said, "Your boys don't realize what they have. They don't know. You took them to China, you did this, and you did that." And I was like, "And, your point is what? Just because they are Native kids they have to suffer? Is that what you are trying to tell me? That just because we've had such a rough start, now my kids, because they are Indian, they have to have a hard life? Why? Tell me why!" (White Spider)

It [martial arts] makes me happy. It also affects my self-esteem because I see myself getting physical defined again. Reducing a lot of body fat and getting stronger affects my self-esteem. As you get better... your self-confidence grows. And if you develop self-confidence in one thing, you carry it wherever you go. I feel better about myself, I tend to be better with everyone else, help other people (Nimky Nene).

I remember talking to [an Aboriginal person].... [She was] talking about [her] car and said, "I don't know if I want to be driving around a [nice, expensive car]". I was looking at [her] saying, "So, just because you're Indian you don't have to be driving around a rez [Rez is a slang reference for First Nations reserve land or Indian reservation] car. We deserve good things in our lives. You know, it's something you earned. It's okay! (White Spider)

[Martial arts] has showed me that I have to work on my self-esteem. I have raised my self-esteem in the time that I've been here. I still need to work on it. If I felt like I was deserving, my self esteem would be in a different place (Turtle).

These quotes provide a glimpse into the lives of these participants and how identity and self-esteem are experienced. The stories also reflect on how a cultural and physical activity program impacted their lives. One of the themes within identity that needs to be addressed is the stigma associated with identifying as Aboriginal. Instilling a sense of cultural pride is important, both within Aboriginal people as well as dispelling the stereotypes that exist among non-Aboriginal people. Programs, such as the North American Indigenous Games described earlier play a significant role in increasing the cultural pride of Indigenous 
people. Addressing stigma associated with identifying as Aboriginal, instilling a sense of cultural pride, addressing the sense of undeservingness and dispelling the stereotypes that exist among non-Aboriginal people all help build Aboriginal health, including the Western notion of mental health.

A recommendation for future research is a more in-depth exploration of how Indigenous people experience identity today in light of the past colonial activities and current stigma of being Indigenous. These experiences may be similar throughout global communities but there would undoubtedly be differences as well. While this in-depth analysis may be interesting in itself, it might also provide specific answers on how to develop future programs.

\section{Beyond Recovery: Healing for Indigenous People}

In 2004, noted mental health activist Mary O'Hagan wrote that most recovery literature has been very monocultural. Based in New Zealand and informed by Maori teachings, she argued that we need instead "to acknowledge cultural diversity and a connection to one's own culture as a key to recovery" (O'Hagan 2004, p. 2). It follows then that for Indigenous Peoples mental health cannot be understood without acknowledging cultural practices such as the Medicine Wheel and looking at physical, mental, emotional and spiritual well-being. It also stands to reason that interventions or programs targeting mental health recovery cannot simply target mental health.

For Indigenous peoples, going beyond Western notions of recovery and toward true healing is undeniably complex. Yes, it is about lived or real life experience, overcoming challenges (Deegan 1988), peer support and self-care, but it is also inextricably bound to colonization, identity, the broken spirit and an awareness of body, mind and community. An Indigenous healing model admits that the wounded identity of Indigenous people needs to be addressed by allowing people to learn about their spiritual and cultural traditions, instilling Native pride so people will want to self-identify and learn about their culture, and most importantly, passing this healthy behaviour down to the next seven generations. As demonstrated through the research, it means building self-esteem as well as recognizing and working against feelings of undeservingness. Healing must also begin with an Indigenous understanding of mental health. For the Anishnaabe, that understanding is guided by teachings and knowledge such as the Medicine Wheel and the Seven Generations. It means being in the body through physical activity programs and cultural activities. It means that Western mental health practitioners acknowledge, accept and make available different Nation teachings - as seen in the example of the Elder at CAMH. Healing also means engaging in the specific cultural and spiritual practices of one's particular Nation with joy and pride. This embracing of Indigenous knowledges and teachings, this restoring of Indigenous identities and this recognition of strengths and cultural pride will not only move Indigenous people beyond the limits of mental health recovery toward authentic healing but will impact the next seven generations. Recovery advocates take note!

\section{References}

Aboriginal Youth Drug Strategy. (2009). Harm Reduction Trainer's Manual. Ontario Federation of Indian Friendship Centres. Toronto. Retrieved on January 13, 2009, from http://www.dopendn.ca/HarmRe duction.pdf. 
Anishnawbe Health Clinic. (2006). Anishnawbe health brochure. Toronto: Anishnawbe Health.

Armitage, A. (1995). Comparing the policy of aboriginal assimilation: Australia, Canada, and New Zealand. Vancouver: UBC.

Baskin, C. (2005). Circles of inclusion: Aboriginal world views in social work education. Ph.D. dissertation, University of Toronto (Canada), Retrieved June 2, 2008, from Dissertations \& Theses: Full Text database. (Publication No. AAT NR27745).

Blackstock, C. (2008). Rooting mental health in an Aboriginal worldview. Ottawa: Provincial Centre of Excellence for Child and Youth Mental Health.

Buti, A. (2002). The removal of Aboriginal children: Canada and Australia compared. University of Western Sydney Law Review. Retrieved January 7, 2009, from http://www.austlii.edu.au/au/journals/UWSLRev/ 2002/2.html.

Carpenter, J. (2002). Mental health recovery paradigm: implications for social work. Health and Social Work, 27(2), 86-94.

Cheng, R., Church, K., Costa, L., Harris, D., Moffatt, K., Mohammed, S., et al. (2008). Mental health recovery: Users and refusers. Final report on "Nothing about us without us:" What do psychiatric survivors in Toronto think about mental health "Recovery"?. Toronto: Wellesley Institute.

Church, K. (2004). Mad people's history: An outsider's account of psychiatric survivor activism in english Canada. A paper presented to the Fifth Asian Non-Government Organizations Forum, Taipei City, Taiwan.

Colmant, S. A. (2000). U.S. and Canadian boarding schools: a review, past, and present. Native Americas Hemispheric Journal of Indigenous Issues, 17(4), 24-48.

Deegan, P. E. (1988). Recovery: the lived experience of rehabilitation. Psychosocial Rehabilitation, 11(4), 11-19.

Dion Stout, M., \& Kipling, G. (2003). Aboriginal people, resilience and the residential school legacy. Ottawa: Aboriginal Healing Foundation. Retrieved on 4 February 2007 from: http://www.ahf.ca/.

Eigenbrod, R., Kakegamic, G., \& Fiddler, J. (2003). Aboriginal literatures in Canada: A teacher's resource guide. Ottawa: Curriculum Services Canada.

Elliott-Farrelly, T. (2004). Australian Aboriginal suicide: the need for an Aboriginal suicidology? Australian e-Journal for the Advancement of Mental Health, 3(4). Retrieved January 7, 2009, from http://www. auseinet.com/journal/vol3iss3/elliottfarrelly.pdf.

Harding, C. M., Brooks, G. W., Ashikaga, T., Strauss, J. S., \& Breier, A. (1986a). The Vermont longitudinal study of persons with severe mental illness: 1 . Methodology, study sample and overall status 32 years later. American Journal of Psychiatry, 144, 718-725.

Harding, C. M., Brooks, G. W., Ashikaga, T., Strauss, J. S., \& Breier, A. (1986b). The Vermont longitudinal study of persons with severe mental illness: II. Long-term outcome of subjects who retrospectively met DSM-II criteria for schizophrenia. American Journal of Psychiatry, 144, 727-735.

Health Canada. (2006). First nations, Inuit and Metis: Suicide prevention. Retrieved January 7, 2009 from http://www.hc-sc.gc.ca/fniahspnia/promotion/suicide/index-eng.php.

Jacobson, N., \& Curtis, L. (2000). Recovery as policy in mental health services: strategies emerging from the states. Psychiatric Rehabilitation Journal, 23(4), 333-341.

Jacobson, N., \& Greenley, D. (2001). What is recovery? A conceptual model and explication. Psychiatric Services, 52(4), 482-485.

Jimenez, M. A. (1988). Chronicity in mental disorders: evolution of a concept. Social Casework, 69, 627-633.

Kirmayer, L., Brass, G., \& Tait, C. (2000). The mental health of Aboriginal peoples: transformations of identity and community. Canadian Journal of Psychiatry, 45, 607-616.

Kirmayer, L., Brass, G., Holton, T., Paul, K., Simpson, C., \& Tait, C. (2007). Suicide among Aboriginal people in Canada. Ottawa: Aboriginal Healing Foundation.

Lavallée, L. (2007). Physical activity and healing through the medicine wheel. Pimatisiwin-Journal of Aboriginal and Indigenous Community Health, 5(1), 127-153. Retrieved on July 26, 2007 from http:// www.pimatisiwin.com/Articles/5.1F_Physical_Activity_and_Healing.pdf.

Lavallée, L. (2008). Balancing the medicine wheel through physical activity. Journal of Aboriginal Health, 4(1) Retrieved April 24, 2008 from http://www.naho.ca/english/journal/jah04_01/09MedicineWheel_64-71.pdf.

Lavallée, L. (2009). Practical application of an indigenous research framework and Indigenous research methods: sharing circles and Anishnaabe symbol-based reflection. International Journal of Qualitative Methods, 8(1), 21-40. Retrieved April 28, 2009 from http://ejournals.library.ualberta.ca/index.php/ IJQM/article/view/943/5195.

Lavallée, L., Thorne, D., Day, K., Thorne, T., \& Matchiwita, S. (2009). 2008 North American indigenous games health and social impact survey and fitness testing report. Toronto: Community report.

Mead, S., \& Copeland, M. E. (2000). What recovery means to us: consumers' perspectives. Community Mental Health Journal, 36(3), 315-328. 
National Aboriginal Health Organization. (2005). First nations regional longitudinal health survey (RHS) 2002/03: The peoples' report. Ottawa: National Aboriginal Health Organization.

National Association of Friendship Centres. (2006). National association of friendship centres history. Retrieved July 20, 2006, from www.nafcaboriginal.com/history.htm.

Native Canadian Centre. (2006). Native Canadian centre martial arts. Retrieved July 20, 2006, from http:// www.ncet.on.ca/martialartsprogram.html.

North American Indigenous Games. (2002). North American indigenous games history, Retrieved on January 12, 2009 from http://www.2002naig.com/english2/about_history.html.

O'Hagan, M. (2004). Recovery in New Zealand: lessons for Australia? Australian e-Journal for the Advancement of Mental Health, 3(1), 1-3.

Poole, J. (2007). Behind the rhetoric of hope: A critical analysis of recovery discourses in Ontario. Unpublished Doctoral Dissertation. University of Toronto: Toronto.

Poole, J. (2008). The language of recovery. In Psychiatric Patient Advocate Office (Ed.), Honouring the past, shaping the future: 25 years of progress in mental health advocacy and rights protection (pp. 104-106). Toronto: The Queen.

Restoule, J. P. (2006). Male Aboriginal identity formation in urban areas: A focus on process and context. Doctoral thesis. University of Toronto: Toronto.

Richmond, C., \& Ross, S. (2009). The determinants of first nation and Inuit health: a critical population health approach. Health \& Place, 15, 403-411.

Roberts, C. (2004). Powwow history. Retrieved January 3, 2004, from http://www.powwowcountry.com/ powwow_history.htm.

Sinclair, R. (2007). Identity lost and found: lessons from the sixties scoop. First Peoples Child and Family Review, 3(1), 65-82.

Trocme, N., Knoke, D., \& Blackstock, C. (2004). Pathways to over-representation of Aboriginal children in Canada's child welfare system. Social Services Review, 78(4), 577-600.

U.S. Department of Health and Human Services. (2001). Trends in Indian Health. Indian Health Service, Office of Public Health Office of Program Support, Division of Program Statistics.

Wesley-Esquimaux, C., \& Smolewski, M. (2004). Historic trauma and Aboriginal healing. Ottawa: Aboriginal Healing Foundation. 